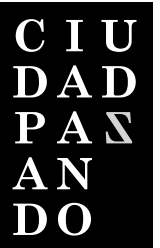

PENSANDO REGIONES

Artículo de revisión de tema

\title{
La paz en el municipio de Barrancabermeja y el reto paramilitar
}

Peace in the municipality of Barrancabermeja and the paramilitary challenge

Paz no município de Barrancabermeja e o desafio paramilitar

\section{Camilo Arturo Suárez Rojas ${ }^{1}$}

\section{Miguel Ángel Gómez Ossa²}

\section{Carlos Arturo Suárez Fajardo ${ }^{3}$}

Para citar: Suárez, C., Gómez, M. y Suárez, C. (2018). La paz en el municipio de Barrancabermeja y el reto paramilitar. Revista Ciudad Paz-ando, 11(1), pp. 74-82. doi: https://doi.org/10.14483/2422278X.12219

Fecha de recepción: 17 de junio de 2017

Fecha de aprobación: 20 de febrero de 2018

\footnotetext{
1 Estudiante de Ciencia Política y Gobierno, Universidad de Bogotá Jorge Tadeo Lozano, Colombia. Correo electrónico: camilo.suarezr@utadeo.edu.co 2 Estudiante de Ciencia Política y Gobierno, Universidad de Bogotá Jorge Tadeo Lozano, Colombia. Correo electrónico: miguela.gomezo@utadeo.edu.co 3 Doctor en Telecomunicaciones, Universidad Politécnica de Valencia, España. Docente titular Facultad de Ingeniería, Universidad Distrital Francisco José de Caldas, Colombia. Investigador del Observatorio de Construcción de Paz, Universidad de Bogotá Jorge Tadeo Lozano, Colombia. Correo electrónico: csuarezf@udistrital.edu.co
} 


\section{RESUMEN}

El presente artículo analiza e interpreta el accionar de nuevos grupos armados al margen de la ley que están relacionados con el fenómeno paramilitar, esto teniendo como referente geográfico el Magdalena Medio y, específicamente, el municipio de Barrancabermeja. Se arguye entonces en el presente artículo que una solución al fenómeno paramilitar se debe sustentar bajo la teoría de gestión de conflictos propuesta por el investigador y experto en paz y solución de conflictos Peter Wallesteen.

Palabras clave: gestión de conflictos, Magdalena Medio, narcotráfico, paramilitarismo.

\section{ABSTRACT}

This article analyses and interprets the actions of new armed groups outside the law that are related to the paramilitary phenomenon, this having as geographic referent the middle Magdalena and specifically the municipally of Barrancabermeja. For this reason, it is argued in this article that a solution to the paramilitary phenomenon must be underpinned by the theory of conflict management proposed by researcher and expert on peace and conflict resolution Peter Wallesteen.

Keywords: conflict management, drug trafficking, Middle Magdalena, paramilitarism.
O artigo analiza e interpreta a ação de novos grupos armados à margem da lei que estão relacionados con o fenómeno paramilitar, tendo como referente geográfico a região de Magdalena Medio, e, específicamente, o municipio de Barrancabermeja. Argumenta-se que uma solução ao fenómeno paramilitar deve sustentar-se na teoria de gestão de conflitos proposta pelo investigador para a paz e especialista em resolução de conflictos, Peter Wallensteen.

Palavras-chave: gestão de conflitos, Magdalena Medio, o tráfico de drogas, paramilitarismo. 


\section{Introducción}

El presente escrito tiene como propósito profundizar en una problemática de seguridad muy importante para la ciudad más industrializada e importante del Magdalena Medio, Barrancabermeja. Se trata del surgimiento de grupos sucesores del paramilitarismo, los cuales se siguen alimentando de varias variables que le dieron forma al paramilitarismo desde hace muchos años.

Es importante tener en cuenta que el origen del presente artículo tiene como una de sus fuentes un escrito presentado para la asignatura "Análisis de conflictos y construcción de paz" del programa de Ciencia Política y Gobierno de la Universidad Jorge Tadeo Lozano.

El fenómeno paramilitar en Colombia, ubica sus inicios en la época de la Violencia. Aunque normalmente se dice que el inicio de esta época se da con el asesinato del líder liberal Jorge Eliecer Gaitán, es necesario tener en cuenta que la Violencia inició con la llegada de los conservadores al gobierno, lo cual llevó a una violencia bipartidista generalizada en el país, también se puede anotar que en el auge de la violencia, los comunistas se ven golpeados y es el inicio de las autodefensas comunistas, las cuales tenían la función de oponer una resistencia a la violencia estatal y paraestatal.

Los gobiernos de los conservadores Mariano Ospina, Laureano Gómez y el breve gobierno de Roberto Urdaneta se enmarcan en una violencia generalizada, la cual se caracteriza por una guerra abierta contra los liberales y los comunistas, lo anterior haciendo uso de las fuerzas legales del Estado, pero también de la creación de grupos como los "Pájaros" y la "policía Chulavita", organizaciones paramilitares. Así, "Los gobiernos conservadores de Mariano Ospina primero, y de Laureano Gómez después, instauran el estado de sitio, y desatan una guerra contra los liberales y los comunistas, contando la policía 'Chulavita"” (Bello,1958, p. 58).

El uso de ejércitos paramilitares o privados por parte del Estado, terratenientes y empresarios, se extendió hasta el principio del frente nacional y marcaria una práctica militar que, lejos de desaparecer, se recicló durante muchos años hasta el día de hoy. Uno de estos primeros "reciclajes" fue la creación de ejércitos paramilitares en Puerto Boyacá en la década de los 80 , estructuras que fueron creadas en asocio con fuerzas armadas, terratenientes y empresarios de lo lícito y lo ilícito.

los paramilitares, como grupo armado, estaban marcados por su carácter de subordinación a otros actores del conflicto, eran estructuras de guerra construidas en paralelo a otras estructuras con intereses superiores a los suyos. Constituían el músculo de la violencia, intimidación y la protección de los intereses de terceros, como intereses de terceros, como terratenientes, élites regionales, políticos profesionales, narcotraficantes, sectores de extrema derecha en el establecimiento, las fuerzas armadas, etc. (Duncan, 2015, p. 275).
En la década de los 80 se comienzan a crear ejércitos paramilitares con el auspicio de políticos y terratenientes en la región del Magdalena Medio, donde nace la llamada "capital antisubversiva de Colombia", el municipio de Puerto Boyacá. Los ejércitos paramilitares, son responsables de varios asesinatos y masacres en esta región del país, aunque es necesario aclarar que los primeros grupos de este tipo no estaban tan bien equipados y financiados como los grupos que le sucedieron.

Luego, en los 90, se comienza a gestar un nuevo "reciclaje" del paramilitarismo en Colombia, se trata del proyecto de autodefensas de los hermanos Castaño y más específicamente de Carlos Castaño. Con la muerte de Fidel Castaño y el ascenso de Carlos Castaño, se comienza un proceso que culmina en la creación de las Autodefensas Unidas de Colombia, este proceso se caracteriza por la articulación de los grandes jefes y sus ejércitos privados a la gran estructura de las AUC, "el objetivo de Castaño era reunir todos los ejércitos privados del país bajo un solo mando, alrededor de una organización con un discurso ideológico contrainsurgente, políticamente unificada y con la disciplina necesaria" (Duncan, 2015, p. 337-338). Este proyecto de Castaño, tenía unos problemas estructurales desde su misma creación.

A pesar de que se logró reunir a los más grandes jefes paramilitares en las AUC, este proyecto carecía de una articulación completa y era más una confederación en términos organizativos, esto provocó que desde un principio existieran serias divisiones entre las facciones integrantes, lo que no solo fue un problema para las AUC, sino que fue un problema peor a la hora de desarticular esta estructura.

Luego del proceso que pretende desarticular la organización paramilitar, las AUC se terminan de desintegrar entre los que cooperan con la justicia y los que deciden seguir en actividades ilícitas. Quienes que deciden continuar en sus antiguas actividades, son una de las fuentes más importantes de las nuevas estructuras sucesoras del paramilitarismo. Es preciso mencionar que la estructura más importante en este aspecto es el denominado Clan Usuga, esta estructura fue creada con las Águilas Negras, de Vicente Castaño, y con las Autodefensas Gaitanistas de Colombia, una de las que en la actualidad tiene presencia en el Municipio de Barrancabermeja.

En cuanto a Barrancabermeja, es preciso anotar que el Magdalena Medio fue una de las cunas del paramilitarismo. Esta zona rica en recursos naturales, ha sido históricamente una zona en disputa para los actores armados, situación que se mantiene hasta hoy.

Barrancabermeja es, desde mediados del siglo XX, un enclave industrial importante para el país, lo que se refleja sobretodo en la industria petrolera que se formó con la Tropical Oil Company; posteriormente, esta empresa se vuelve pública ante la presión sindical que se desarrolla, lo que dio origen a la empresa estatal de Ecopetrol. 
La lucha sindical que se ha desarrollado en este municipio, tiene actualmente como uno de sus referentes más importante a la Unión Sindical Obrera (USO), este relevante sindicato ha sido blanco del paramilitarismo desde hace varios años, teniendo en cuenta que las nuevas formas recicladas del paramilitarismo no han cesado en su persecución.

Es importante agregar que el accionar paramilitar en este municipio también se ve reflejado en lo de ellos denominan "limpiezas sociales" y demás formas de control social como la prohibición de la prostitución, la prohibición de la protesta y la prohibición de pertenecer a determinadas organizaciones sindicales, sociales y políticas.

\section{Marco teórico}

El enfoque teórico que se usará en esta investigación es el de la gestión de conflictos. Hablar de gestión de conflictos es introducirse en un campo donde, más que definiciones taxativas, a menudo se encuentran diversas características que suelen referirse a la misma cosa; aunque autores como Wallensteen (2007) manejan un concepto del conflicto que va más allá del simple comportamiento de los actores en disputa, está más bien orientado a que obedecen a una conducta subordinada hacia las dinámicas del sistema dominante (donde se compite y se enfrenta a situaciones concretas), es por ello que si se busca una definición explícita debe partirse de la expresión conflict management; en dicho modo - y siguiendo la traducción del inglés-, el concepto de gestión de conflictos debe ser analizado desde la perspectiva del "manejo de conflicto", o también desde la óptica de la "intervención del conflicto", siguiendo las pautas de Moore (1995), quien señala que es necesaria la participación de actores públicos y privados así como de un tercero autorizado legalmente que se crucen entre las etapas de evitación e intervención del conflicto.

Una de las ideas clave para entender el ámbito de la gestión del conflicto es la "mediación", o como lo define Six (1997) "el ámbito de intervención de un tercero" (p.17), es decir, puede ser visto como un proceso que busca desbloquear un conflicto a partir de la intervención de un tercero cuyas capacidades propias permiten hallar una solución sin mayores dificultades. Vicenc Fisas cita a Cris Mitchell, quien a su vez se refiere a la figura del mediador como "una figura del proceso, que conocemos como "facilitador", pero que no puede actuar en solitario, sino que necesita del concurso de otras personas que realizarán otras tareas igualmente necesarias en un proceso de paz" (Fisas, 1998, p. 3).

Haciendo una revisión del tema, se llega a la conclusión en concordancia con el investigador coreano Jeong (1999), quien afirma que "no hay una definición precisa del concepto de gestión y resolución de conflictos" ( $p$. 390); sin embargo, las teorías expuestas por Yarn (1999), Deutsh, Coleman y Marcus (2006), Wallensteen (2002),
Moore (1995), entre otras, permiten tener un hilo conductor hacia el empoderamiento y el reconocimiento de características del tema a tratar en la investigación, los cuales servirán como instrumentos adecuados para una gestión pacífica del conflicto entre el gobierno colombiano y los reductos del paramilitarismo en la zona de Barrancabermeja.

La razón de lo anterior se sustenta en que este tipo conflicto que enfrenta al estado colombiano y a los núcleos paramilitares, dado su grado de descomposición y características propias, hacen necesario el uso de distintos mecanismos para gestionar desde un punto de vista pragmático (realista) determinadas acciones que podrían calificarse como eficaces en la lucha contra las estructuras sucesoras del paramilitarismo. De dicho modo, se hará uso de recursos teóricos de algunos de los máximos exponentes del modelo de gestión de conflictos, planteado como la práctica política del paradigma realista.

En primer lugar, es necesario comenzar por definir y caracterizar el realismo político para luego tener una idea más clara acerca de la gestión de conflictos que se plantea en esta investigación como la salida al conflicto frente a los actores paraestatales. El realismo político es un conjunto de supuestos que, en forma de axiomas, sustentan una construcción teórica de principios clásicos tales como "la naturaleza humana", planteada por Hobbes, Morgenthau o teóricos más antiguos como Tucídides, donde se resalta que unos principios inherentes a la condición humana se sobreponen a otros. De acuerdo con el profesor Clulow (2013), del Departamento de Relaciones Internacionales de la Universidad ORT de Uruguay, el "núcleo duro" del paradigma realista puede basarse en cuatro principios tales como:

- Los estados son los principales actores de las Relaciones Internacionales.

- Un estado debe ser unitario y racional.

- Los intereses nacionales, entendidos desde un enfoque de seguridad nacional, deben ser la principal preocupación de un estado y del mismo modo deben así guiar su política internacional.

- La anarquía es el sistema o normaimperante en el accionar de los estados en medio del Sistema Internacional.

Bajo este orden de ideas, el principio realista ha sido la teoría dominante en áreas como las RRII y la Ciencia Política; sin embargo, su validez ha sido bastante cuestionada, en especial luego de la Guerra Fría, motivado entre otras razones por las preferencias fijas y excluyentes que mantuvieron los estados teniendo orientación en términos absolutos y, por consiguiente, reduccionistas de las distribuciones de poder dentro del sistema internacional.

Normalmente, los pensadores realistas piensan que el hombre, su racionalidad y sus deseos de poder son el eje por el cual debe girar el sistema, ya sea este estatal o 
internacional; para Morgenthau (1950) el rol de los hombres de estado bajo se distingue en tres tipos:

- El realista, que piensa y acota en términos de poder.

- El ideológico, que piensa bajo principios morales pero que actúa en términos de poder.

- El moralista que piensa y actúa según sus principios morales.

Siguiendo las características ya mencionadas acerca de la escuela realista, cabe añadirle que por su naturaleza estado-céntrica, otros actores diferentes a los Estados o sus representantes son considerados como poco influyentes dentro del ámbito estatal e internacional, de este modo, la sociedad civil y otros actores subestatales o desvalorizados. En este punto conviene preguntarse, de acuerdo con el paradigma realista, ¿bajo qué principios un estado frente a una situación en la que se pretende dar solución a un conflicto?

"El realismo, es su esencia, un enfoque elitista basado en proceso vertical de decisión" (Barreto, 2012, p. 28), desde el cual se vale de la herramienta conocida como "Track 1" de resolución de conflictos, son los actores principales (líderes políticos, militares, religiosos entre otros) quienes, con base en sus principios e intereses personales, negocian hasta llegar a un resultado de suma no cero (Orso, 2012).

Para expertos como Woodhouse, la gestión de conflictos, se refiere a todas aquellas actividades que se encuentran orientadas no a la búsqueda de resultados, sino a un proceso que tiene como objetivo las causas directas de un conflicto; en este sentido, este modelo le apunta a la satisfacción de las necesidades básicas de los individuos, colectivos u comunidades (Woodhouse, 1999).

Desde una visión más pragmática, no interesa solucionar el problema que condujo al conflicto, sino "gestionarlo", los conflictos son vistos como algo irreal, no es relevante incidir sobre las causas del conflicto $u$ hallar soluciones creativas; se apunta entonces a buscar una intervención entre actores (gestionar) orientado a negociar o debilitar por la vía de la fuerza a la contra parte del conflicto.

\section{Pregunta}

¿Se puede decir que para desarticular las organizaciones sucesoras del paramilitarismo en Barrancabermeja se necesita un enfoque más amplio que la estricta confrontación militar?

\section{Hipótesis}

La hipótesis central del presente trabajo es la siguiente: para el desmonte efectivo de las organizaciones paramilitares se necesita una política estatal integral que incluya sus redes de apoyo, sus fuentes de financiación e investigar los posibles vínculos entre la fuerza pública y estas organizaciones.

\section{Desarrollo}

\section{Gestión integral al problema paramilitar}

Una de las dimensiones más importantes en torno al paramilitarismo son sus fuentes de financiamiento. En cuanto a este tema, es notable que las fuentes económicas del último reciclaje paramilitar son muy similares a las que tenían las AUC; así, entre las fuentes de financiamiento que se encuentran, puede destacarse la que relaciona a empresas con el financiamiento del paramilitarismo "bananeros, ganaderos y comerciantes aportaron todos; las comercializadoras Uniban, Banacol, Sunisa, Proban, Del Monte, Banadex y Augura cancelaron dineros con conocimiento de que iban hacia los paramilitares; ninguna de estas firmas denunció supuestas extorsiones” (Laverde, 2012).

En cuanto a este tema, el grupo de investigación "Estado, Conflictos y Paz" de la Universidad Javeriana, publicó una base de datos construida con sentencias de los tribunales de Justicia y Paz. Los resultados muestran que 57 empresas estarían presuntamente involucradas con la financiación del paramilitarismo, aunque es necesario tener en cuenta que las redes de apoyo económico que tienen los paramilitares, son más amplias. Grupos económicos están ligados al accionar y a la creación de los ejércitos antirrestitución de tierras, los cuales han operado en varias regiones de país.

Por otro lado, se debe tener en cuenta que estas estructuras neoparamilitares tienen redes de apoyo en las ciudades y Barrancabermeja no es la excepción. Gran parte del accionar paramilitar se debe a las acciones de sus fuerzas urbanas y sus redes de apoyo. Entre las actividades que se dan gracias a las redes de apoyo urbano, se pueden nombrar los asesinatos selectivos, las limpiezas sociales, actividades económicas (microtráfico de drogas y la extorsión) y amenazas e intimidaciones.

Se puede afirmar que una gestión más eficaz en cuanto al problema paramilitar debe tener una concepción integral que considere una acción contra sus redes de apoyo, entre estas las empresariales, las rurales y las urbanas. Esta integralidad para combatir el problema es un enfoque clave para una posible desarticulación del paramilitarismo en Barrancabermeja.

\section{Rompimiento definitivo de los vínculos entre fuerzas armadas y paramilitarismo}

El papel de las fuerzas armadas en cuanto a la creación del paramilitarismo en Colombia fue muy destacable y se articuló muy bien con la política contrainsurgente en el país. Como se destacó en la introducción, el paramilitarismo en Colombia fue también una táctica contrainsurgente que desde distintos gobiernos se ha ido reciclando, por esto existe un vinculo histórico entre este actor ilegal y las fuerzas armadas.

A pesar de que la cooperación entre la fuerza pública y el paramilitarismo no es la misma de hace algunos 
años, sí es persistente en algunas regiones una posible cooperación atomizada y la coexistencia pacifica entre nuevas formas de paramilitarismo y la fuerza pública, lo anterior se ha podido constatar en varias partes del territorio nacional.

Para comprender la realidad actual, es necesario señalar la posición del gobierno nacional en cuanto al accionar de estas estructuras criminales, el "negacionismo". Esta postura pretende invisibilizar no solo las acciones violentas de estos grupos, sino que también dudan de la existencia misma de las estructuras paramilitares en el territorio nacional.

Amnistía Internacional señala en su reciente informe "Continúan los años de soledad" que uno de los problemas en cuanto al tema del paramilitarismo, es que el Estado insiste en su inexistencia:

A pesar de la evidencia de incursiones paramilitares, especialmente de Autodefensas Gaitanistas de Colombia, el Estado colombiano continúa negando que estos grupos operen en el territorio. El Ministro de Defensa, en declaraciones emitidas en enero de este año aseguró que en Colombia no hay paramilitarismo, negando no sólo las denuncias de las comunidades, sino también, reforzando la negación sistemática del Estado por reconocer estas estructuras armadas que tantas víctimas han ocasionado (Amnistía Internacional, 2017, p. 21).

Llama la atención que la primera recomendación que hace Amnistía Internacional al Estado colombiano en este informe, es la siguiente "Desmantelar plenamente todos los grupos paramilitares e investigar sus vínculos con las fuerzas de seguridad del Estado" (Amnistía Internacional, 2017, p. 41). Esta recomendación que se soporta en las denuncias que las comunidades hacen, muestra que uno de los elementos que pueden incidir en el accionar paramilitar es la posible coexistencia y, peor aún, la cooperación atomizada entre los cuerpos de seguridad del Estado y los grupos paramilitares.

Una entrevista que hace el noticiero Noticias Uno a miembros de las fuerzas especiales del ejército en
Corinto-Cauca, muestra los alcances de la decrepita doctrina que aún existe en el ejercito nacional. Estos militares no solo están en contra del proceso de paz, sino que además hacen apología al paramilitarismo, textualmente el soldado manifiesta lo siguiente: "Había un lema que utilizaba Carlos Castaño, el paramilitar Carlos Castaño que era: la paz no se hace con diálogos, la paz se hace es con plomo".

\section{Factores y actividades que facilitan la operación de grupos paramilitares en Barrancabermeja}

El puerto petrolero - como se le conoce a Barrancabermeja - ha recibido numerosas y variadas incursiones de grupos paramilitares y de justicia privada desde los últimos veinte años; sin embargo, cabe decir que desde finales de los 90 estas entraron a disputarse el control de los barrios populares de la ciudad.

Recientemente, las condiciones de la ciudad (ubicación estratégica, boom inmobiliario, falta de empleo, alta deserción escolar etc.) están dadas para que estos grupos creen redes de apoyo y busquen ganar el apoyo de la población; en la ciudad, estas redes se presentan como actores garantes de seguridad, con base en el ejercicio de la vigilancia en los barrios populares y en la eliminación —o limpieza social- de posibles guerrilleros y delincuentes comunes.

Sin embargo, en su intento por granjear apoyo social entre la población, muchas de sus prácticas realizables - similares a las de las guerrillas - hacen que pierdan credibilidad y aceptación; por ejemplo, se sabe que hoy en día controlan el negocio del robo de gasolina, también realizan extorsiones a sectores económicos y, aunque no es una actividad nueva en ellos, desde 1999 aparecen entre las listas de quiénes llevan a cabo secuestros selectivos en la ciudad, como lo demuestra la Tabla 1.

Infortunadamente, Barrancabermeja y la región del Magdalena Medio en general son uno de los escenarios más propicios para que las estructuras paramilitares obtengan ganancias económicas de otra actividad ilícita: el microtráfico. En uno de sus informes semestrales, el Observatorio de Paz Integral del Magdalena Medio aduce que:

Tabla 1. Secuestros en Barrancabermeja - Santander 1992, mayo de 2001

\begin{tabular}{|l|c|c|c|c|c|c|c|c|c|c|c|}
\hline \multicolumn{1}{|c|}{ Autor } & $\mathbf{1 9 9 2}$ & $\mathbf{1 9 9 3}$ & $\mathbf{1 9 9 4}$ & $\mathbf{1 9 9 5}$ & $\mathbf{1 9 9 6}$ & $\mathbf{1 9 9 7}$ & $\mathbf{1 9 9 8}$ & $\mathbf{1 9 9 9}$ & $\mathbf{2 0 0 0}$ & $\mathbf{2 0 0 1}$ & Total \\
\hline Autodefensas & 0 & 0 & 0 & 0 & 0 & 0 & 0 & 5 & 4 & 5 & 14 \\
\hline ELN & 19 & 7 & 0 & 4 & 0 & 3 & 25 & 8 & 9 & 0 & 75 \\
\hline Desconocido & 21 & 4 & 4 & 5 & 5 & 2 & 2 & 60 & 26 & 5 & 134 \\
\hline EPL & 0 & 0 & 0 & 1 & 0 & 1 & 3 & 2 & 0 & 0 & 7 \\
\hline FARC & 0 & 0 & 1 & 0 & 0 & 0 & 1 & 1 & 4 & 1 & 8 \\
\hline Total & 40 & 11 & 5 & 10 & 5 & 6 & 31 & 76 & 43 & 11 & 238 \\
\hline
\end{tabular}

Fuente: Observatorio del Programa Presidencial de Derechos Humanos y Derecho Internacional Humanitario, diciembre de 2001, Bogotá D. C. 
Estas estructuras están convirtiendo a Barrancabermeja en una gigantesca plaza de distribución y comercialización de grandes cantidades de alucinógenos, y de paso la han convertido en un sitio apropiado para 'lavar' dinero producto de sus actividades ilegales que se realizan en la región (Observatorio de Paz, 2016).

Los pobladores víctimas de los numerosos flagelos, entre los que además se cuentan extorsiones o vacunas a comerciantes, conocen intuitivamente que los encargados de las finanzas y las operaciones son individuos adscritos a grupos paramilitares, cuyos recursos son destinados para el sostenimiento de sus estructuras y, asimismo, para buscar otras fuentes de financiamiento; de allí que grupos como el Clan Usuga, Los Urabeños o las denominadas Autodefensas Gaitanistas de Colombia, busquen por distintos medios hacerse con el control de estos negocios ilegales en la ciudad. A continuación, un panfleto amenazante dirigido a la población del municipio de Barrancabermeja de parte de las Autodefensas Gaitanistas de Colombia (Figura 1).

Según testimonios de algunos pobladores de las comunas uno, tres, cuatro, cinco y seis de Barrancabermeja, la estructura de Los Urabeños está ideando un plan de exterminio hacia grupos paramilitares, con el fin de monopolizar el negocio de la criminalidad de la ciudad (Observatorio de Integral de Paz, 2016).

La ofensiva que adelantan estas estructuras, y en especial la conocida como Los Urabeños, preocupa demasiado a la población civil y a las autoridades correspondientes de la ciudad, de hecho, se plantea que entre los riesgos de combatir efectivamente a estos grupos la ciudadanía se hallaría frente a: "El dilema, por tanto, es si le apostamos a la ruta de la vida o a la ruta de los negocios ilícitos protegidos por la impunidad" (Observatorio de paz, 2016).

Según Wallensteen (2007), este tipo de conflicto entre el Estado y las estructuras que operan en la ciudad podría asumirse como una categoría separada de conflicto armado, llamado Non State Conflict (Conflicto no estatal). Para Wallensteen, no son claras cuáles son las motivaciones de esta violencia, sin embargo, en este caso se observa que las disputas están propiamente dirigidas a controlar un determinado territorio (en este caso Barrancabermeja) para así manejar los recursos que devienen de sus negocios allí establecidos.

Aunque las cifras de violencia descritas en número de personas asesinadas y secuestradas por grupos paramilitares y guerrillas en la ciudad de Barrancabermeja han disminuido significativamente en los últimos tres años, según el Centro de Recursos para el Análisis de Conflictos (CERAC) "la reducción fue del 80\%, al comparar el período de tres años hasta noviembre de 2012 con los tres años siguientes" (2016), esta tasa podría no ser tan positiva si se toma en cuenta que en los últimos años en la ciudad son cada vez más constantes los asesinatos o vendettas entre estos grupos al margen de la ley debido a disputas territoriales por el control de sus negocios ilícitos, a esto se le añaden las extorsiones a empresas contratistas del sector minero energético, empresarios industriales y comerciantes (Observatorio de Paz, 2016).

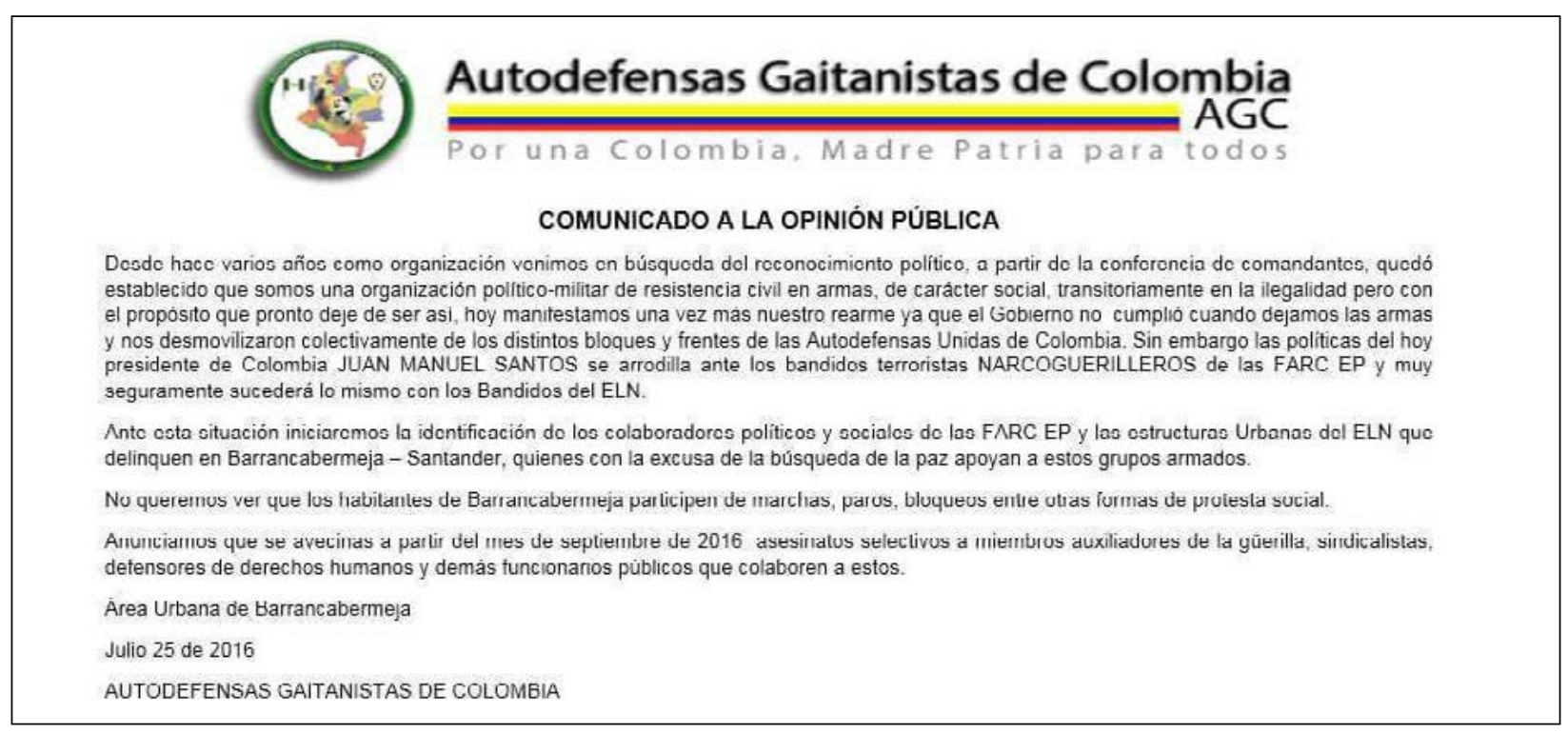

Figura 1. Comunicado público de las AGC a la comunidad de Barrancabermeja

Fuente: León Quiroga, A (2016). En el Magdalena Medio, la paz se ve cada vez más lejana. [Figura]. Recuperado de https://evangelizadorasdelosapostoles.wordpress.com/category/terrorismo-y-violencia/page/169/?iframe=true $\&$ preview $=$ true $\% 2 F f e e d \% 2 F$ 
Cabe mencionar que el Estado colombiano es quien tiene la responsabilidad de asegurar una convivencia pacífica, así como la protección de los derechos; para ello, cuenta con instituciones en cada una de las ramas de poder que son las encargadas de velar por una paz sostenible cuando existen grupos o individuos que atentan contra la permanencia de esta, sin embargo, en el caso de Barrancabermeja - y en muchas otras partes del país - factores como la impunidad y la ineficacia de las instituciones son alicientes para que florezcan diversas modalidades de crimen, en este caso perpetrados por grupos paramilitares. Debido a que esta situación se perpetúa desde los últimos veinte años, aborda a todos el dilema de cómo sería la mejor opción para contrarrestar el accionar de grupos.

Para Deustch y Coleman (2006), una de las estrategias o canales para influir en un sistema social que se encuentra inmerso en un conflicto armado prolongado es método top-down (arriba-abajo), típicamente usado por elites políticas y tomadores de decisiones altamente capacitados, a menudo implica estrategias de mando y control de influencias con efectos rápidos aunque dramáticos en los sistemas sociales; para el caso de Barrancabermeja, en algunas zonas sus habitantes ya se encuentran habituados a un ambiente de conflicto y violencia constante, con resultados nefastos por parte de quienes desean hacer justicia por su propia mano, a este se le añade que los grupos ilegales siguen anidando y generando una mayor descomposición social, por ello se considera que es necesaria la intervención de un tercero que carezca de un poder autorizado de decisión y que examine los componentes de esta situación (Moore, 1995).

En este contexto, la ACORE (Asociación Colombiana de Militares en Retiro), una organización no gubernamental, marcadamente critica a políticas de negociación con grupos armados que impliquen un proceso de peacebuilbing y que más bien demuestra cercanía hacia el modelo de gestión de conflictos; además, por su componente militar idiosincrásico (proestatista, antisubversivo, no revisionista) es el mejor canal de negociación entre el estado colombiano y estos grupos armados ilegales presentes en la ciudad de Barrancabermeja.

\section{Conclusiones}

El paramilitarismo, como elemento táctico recurrente en la estrategia contrainsurgente en Colombia, ha pasado por diversas etapas y en la actualidad se pueden constatar las consecuencias de un desarrollo que ha ido mutando hasta una condición mucho más descompuesta y atomizada que lo caracteriza actualmente, lo anterior se debe al proceso de desarticulación de la organización confederada AUC.

Barrancabermeja y la región del Magdalena Medio se presentan históricamente y en la actualidad como uno de los escenarios más golpeados por el paramilitarismo, es la razón por la que se toma como referente para este trabajo la situación en esta parte del territorio nacional. La dinámica actual en los territorios muestra los grandes desafíos a los cuales debe enfrentarse el Estado colombiano si quiere disminuir la violencia.

Se requiere que el Estado colombiano reconozca el problema actual y salga de la obstinada postura negacionista que le ha impedido conocer las dimensiones del problema actual, asimismo, ha impedido dar el tratamiento adecuado al problema que enfrentan varias regiones del país. Es preocupante que a la fecha existan 38 excombatientes de las Farc asesinados, así como 208 líderes sociales asesinados desde el comienzo la implementación de los acuerdos de la Habana, según datos del Instituto de Estudios para el Desarrollo y la Paz. Asesinatos que en muchos casos estaban precedidos por amenazas e intimidaciones de las organizaciones paramilitares.

En este sentido, llama la atención que en el acuerdo de paz de la Habana se plantease en el punto quinto el desmantelamiento de las organizaciones sucesoras del paramilitarismo y sus redes de apoyo mediante la Unidad Especial de Investigación, pero al mismo tiempo el gobierno niega la existencia de estructuras criminales con esta naturaleza y muestra poco interés en implementar lo acordado en esta materia. También es necesario que se comiencen a investigar los posibles vínculos o la pasividad que tendrían algunos miembros de la fuerza pública con las nuevas organizaciones paramilitares.

En cuanto a la solución propuesta, se presenta una de corte integral basada en la teoría de la gestión de conflictos, la cual debe tener además de la confrontación armada, elementos como el desmantelamiento de las distintas redes de apoyo y financiamiento, y la posibilidad de un canal de comunicación que lleve estas estructuras al sometimiento.

\section{Referencias}

Amnistía Internacional. (2017). Continúan los años de soledad. Colombia: Acuerdo de paz y garantías de no repetición en el chocó. Londres: Amnistía Internacional.

Barreto, M. (2016). Laboratorios de paz" en territorios de violencia(s): ¿abriendo caminos para la paz positiva en Colombia?. Bogotá: Fundación Universidad Jorge Tadeo Lozano.

Bello, P. (1980). Colombia: Revolución armada. Nueva Antropología, $4(6), 57-88$.

Clulow, G. (2013). Una visión introductoria a los principios del realismo político. Recuperado de https://dspace.ort.edu.uy/bitstream/item/2737/documentodeinvestigacion96.pdf

Deutsh, M., Coleman, P. y Marcus, E. (2006). The Handbook of Conflict Resolution. Theory and Practice. Jossey Bass.

Duncan, G. (2015). Los señores de la guerra. Bogotá: Penguin Random House Grupo Editorial.

El Tiempo (2016) El mapa de la vergüenza. Recuperado de: http://www.eltiempo.com/colombia/otras-ciudades/el-mapa-de-los-lideres-sociales-asesinados-en-colombia-184408\# 
Fisas, V. (2010). Introducción a los Procesos de Paz. Agencia Catalana de Cooperación al Desenvolupament.

H. (1950). The mainsprings of American foreign policy: the national interest vs. moral abstractions. The American Political Science Review, 44(4), 833-854.

Jeong, H. (1999). Encyclopedia of Violence, Peace and Conflict. Conflict Management and Resolution. San Diego: Academic Press.

Laverde, J. (Diciembre 10 de 2012). Los "pecados" de la Chiquita Brands. El espectador. Recuperado de: http://www.elespectador.com/noticias/judicial/los-pecados-de-chiquita-brands-articulo-391790

Moore, C. (1995). El proceso de Mediación. Métodos prácticos para la resolución de conflictos. Barcelona: Ediciones Granica.

Noticias Uno. (2016). Comandos del Ejército en Corinto, Cauca, dicen que su doctrina sigue siendo la de Carlos Castaño. Recuperado de: https://www.youtube.com/watch?v=V1lYgDH6uo8
Observatorio de Paz Integral. (2016). Barrancabermeja: las estructuras paramilitares fortalecen su poder. Recuperado de http:// www.yariguies.com/portal/userfiles/files/OPI_Informe_BARRANCA_\%2829.1.15\%29.pdf

Orso, J. (2012). Resolución de conflictos en la teoría de las relaciones internacionales: el aporte del enfoque constructivista. Revista In tegracion en Ideas, 4, 101-124.

Six, F. (1997). Dinámica de la mediación. Barcelona: Editorial Paidós.

Wallensteen, P. (2007). Understanding Conflict Resolution. London.

Woodhouse, T. (1999). Resolución de Conflictos Internacionales: Algunas Críticas y una respuesta. Centre for Conflict Resolution, Departamento de estudios de paz, Universidad de Bradford, junio de 1999. 